\title{
LA CIENCIA NUEVA DE VICO: ENTRE LA MATHESIS UNIVERSALIS Y LA LENGUA HEROICA ${ }^{1}$
}

\author{
VINCENZO VITIELLO \\ Università San Raffaelle, de Milán
}

\begin{abstract}
RESUMEN: En la parte primera de este ensayo se muestra, contra la interpretación tradicional de Vico como anticartesiano y filósofo de la historia de la sociedad civil, que la Ciencia Nueva constituye una extensión de la mathesis universalis al mundo histórico. De ello dan fe la axiomática presentada en el libro I (las llamadas Dignidàdes), y la división de las tres edades - de los dioses, de los héroes, de los hombres - en que se distribuye el orden necesario de la historia: la viquiana "historia ideal eterna", sobre la cual "transcurren en el tiempo" las historias de las naciones. En la parte II, dedicada a la lengua heroica, se apuntan las limitaciones de esta mathesis, incapaz de comprehender -como el propio Vico reconoce - en el lenguaje abstracto de la reflexión la edad primera del mundo, el surgimiento de la humanidad histórica a partir de la ingens sylva de la naturaleza. De este modo, Vico restituye a la historia y a la escritura de la historia toda su problemacidad.
\end{abstract}

PALABRAS CLAVE: Verdad,lenguaje, cuerpo, gesto, historia ideal, historia temporal.

\section{Vico's New Science: on mathesis universalis and heroic language}

ABSTRACT: Against the traditional interpretation of Vico as an anticartesian philosopher of civil society's history, the first part of this essay depicts the New Science as an extension to the historical world of the mathesis universalis. This is proved by the axiomatic method present in the first Book (the so called Dignities) and by the division in three ages - of gods, of heroes and of men - of the necessary historical order: Vico's "eternal ideal history", above which the nations' histories "pass by within time». The second part of the article deals with the «heroic language» and shows the limitations of this mathesis, unable to express - as Vico itself admits - through an abstract and reflexive language the first age of the world: the arousal from nature's ingens sylva of the historical human kind. In this way, Vico restores history and historiography with all their problematic complexity.

KEY WORDS: Truth, language, body, gesture, ideal history, temporal history.

\section{Mathesis Universalis}

[...] al cabo se nota que solamente aquellas [disciplinas] en las que se estudia cierto orden y medida hacen referencia a la Mathesis, y que no importa si tal medida ha de buscarse en los números, en las figuras, en los astros, en los sonidos o en cualquier otro objeto; y que, por lo tanto, debe haber una cierta ciencia general que explique todo lo que puede buscarse acerca del orden y la medida no adscrito a una materia especial, y que es llamada, no con un nombre adoptado, sino ya antiguo y recibido por el uso, Mathesis Universalis, ya

1 El presente artículo procede de una Conferencia del Prof. Vincenzo Vitiello impartida en la Universidad Autónoma de Madrid el 30 de octubre de 2013. La traducción española del artículo inédito se debe a Mercedes Sarabia. 
que en ésta se contiene todo aquello por lo que las otras ciencias son llamadas partes de la matemática².

Es necesario que haya en la naturaleza de las cosas humanas una lengua mental común a todas las naciones, la cual atienda de manera uniforme a la sustancia de las cosas factibles en la humana vida social y la explique con todas las diversas modificaciones como aspectos diversos puedan tener esas cosas $[\ldots]^{3}$.

Comencemos con una cita de Del principio único del derecho universal y de su único fin de G. Vico. Concierne a la definición de lo «verdadero» y de lo «cierto» ${ }^{4}$, lo cual resulta fundamental porque nos libra de la definición más conocida, o más citada, de la definición verum ipsum factum (verdadero y hecho son lo mismo $)^{5}$, que da nombre únicamente a un rasgo de la verdad que, por lo demás, ni siquiera es esencial, ya que no concierne al más alto de los conocimientos humanos. La definición del De uno reza: la conformidad de la mente con el orden de las cosas engendra lo verdadero (verum gignit mentis cum rerum ordini conformatio). No estamos aquí desde luego ante una repetición de la fórmula tradicional de la adecuación de la cosa y del intelecto (adaequatio rei et intellectus). La conformatio aquí es ordini rerum: con el orden de las cosas, no en cambio conformidad con las cosas, rebus. Ahora bien, el orden de las cosas es eterno, divino y la mens, a la que nos estamos refiriendo aquí, es la misma ratio divina, creadora del orden. La conformidad de la mente al orden indica, por tanto, la relación necesaria existente entre orden y creación, y por ende entre orden y conocimiento. De ahí se sigue que esa definición de lo «verdadero» sea en primer lugar onto-lógica y, sólo en segundo lugar, gnoseológica: o sea, que concierne principalmente a lo verdadero en cuanto explicitación de la estructura del ens qua ens, independientemente de su aprehensión por parte de un sujeto, como lo que prueba el hecho de que Vico, en muchos lugares, al hacer una versión abreviada de esta definición determine lo verdadero de la siguiente manera: quod rerum ordini conformatur (aquello que es conforme al orden de las cosas) ${ }^{6}$. Ahora bien, «aquello» que se conforma al orden no es la mente - que, en cuanto ratio, es el orden mismo-, sino la cosa, la res, el hecho, que es verdadero si es conforme al orden eterno, y en cuanto se conforma a ese orden, creado por Dios.

Por el contrario, lo «cierto» es, según su definición: conscientia dubitandi secura (conciencia asegurada de la duda), es decir que concierne exclusivamente a la aprehensión subjetiva, por lo cual lo «falso» (lo no verdadero) puede ser «cierto», así como lo «verdadero» puede ser «incierto».

2 Descartes, R., Regulae ad directionem ingenii, Regula IV. A. T. X, 378; trad. esp. J. M. Navarro Cordón, Alianza, Madrid 1984, p. 86.

3 Vico, G., La Scienza Nuova. Le tre edizioni del 1725, 1730 e 1744, a cura di M. Sanna e V. Vitiello, Bompiani, Milano 2012, ed. 1744 (=SN44), Degnità XXII, p. 864.

4 Vico, G., De uno universi iuris principio et fine uno (= De uno), en: Opere Giuridiche $(=O G)$, Sansoni, Firenze 1974, pp. 34-35.

5 VIco, G., De antiquissima italorum sapientia ex limguae latinae originibus eruenda (= De antiquissima), in Id., Opere filosofiche (=OF), Sansoni, Firenze 1971.

${ }_{6}$ Vico, G., Sinopsi del diritto universale, OG, p. 5; De uno, p. 47 (caput XVII). 
El acercamiento viquiano de lo verdadero a lo cierto puede en principio asombrar, dado que ambos pertenecen —como él mismo es el primero en advertir - a ámbitos problemáticos distintos: lógico (u onto-lógico) el uno, gnoseológico el otro. Sin embargo, cesa tal asombro si recordamos aquel paso de la Autobiografía en el que Vico afirma que ya «desde su primera oración» inaugural lo que él ha intentado es identificar el principio «que unifique todo el saber humano y divino ${ }^{7}$. Era necesario a tal fin comprehender también lo «cierto» en lo «verdadero». Ahora bien, en cuanto que lo cierto pertenece a la conciencia, al conscire, a lo scire cum alio, o sea: al cum alio verum noscere - al conocer lo verdadero junto con algo-, es necesario concluir que, aunque lo cierto no sea lo verdadero, es sin embargo pars veri, parte de lo verdadero. En el lenguaje escolástico —utilizado por el propio Vico en otro contexto ${ }^{8}$-, aunque lo cierto no sea un ens, es sin embargo entis: si no «ente», sí es sin embargo propiedad o cualidad del ente.

El problema planteado por Vico — problema que está a la base de la Ciencia Nueva, e insisto en el término «ciencia»— es tan interesante como complejo. Se trata, para dar de él una rápida caracterización lógica, de entender y explicar lo «verdadero» a la vez como «todo» y como «parte». Como «todo», en cuanto que contiene en sí también lo «cierto»; como "parte», en cuanto que no es lo "cierto», sino algo distinto, otro, de él. Lo cual exige que, en lo verdadero, se distinga la superficie del fondo, el aparecer (Erscheinung y Schein, el aparecer y la apariencia, tomados conjuntamente, como veremos) de la esencia, o sea del ser de lo «verdadero».

Superficie y fondo: la imagen nos la sugiere el propio Vico, que distingue entre lo "generado» (genitum), parangonado con la figura geométrica sólida (imago rerum solida, tamquam plasma: una imagen plástica de las cosas, tal como una escultura), y lo "hecho» (factum), parangonado con la figura plana (imago plana, tamquam pictura: imagen plana, tal como una pintura) ${ }^{9}$. Esta distinción nos permite explicar —o sea, analizar y explicitar — una contradicción que se encuentra incluso en el libro I de la Ciencia Nueva, donde en la Sección III sobre los Principios leemos:

[...] en esa densa noche de tinieblas que cubre la antigüedad primera - para nosotros, lejanísima-, aparece la luz eterna y sempiterna de esta verdad que no puede ser puesta en duda de ningún modo, a saber: que este mundo civil ha sido hecho ciertamente por los hombres, en virtud de lo cual se pueden — porque se deben- volver a hallar los principios de aquél, dentro de las modificaciones de nuestra propia mente humana ${ }^{10}$.

En cambio, en la Sección IV, sobre el Método, leemos:

7 VIco, G., Vita di Giambattista Vico scritta da se medesimo, en: Opere (=O), 2 voll., Mondadori, 1999, p. 36.

8 De antiquissima, $O F$, p. 67.

$9 \quad I b .$, p. 63.

10 SN44, pp. 894. 
[...] tal ciencia debe ser una demostración, por así decir de hecho, histórica, de la providencia, porque debe ser una historia de los órdenes que ella, sin atender a consejo humano alguno, y a menudo contra los propósitos de los hombres, ha dado a esta gran ciudad del género humano [a este gran Estado que constituye el género humano], pues, aunque este mundo haya sido creado en el tiempo y sea particular, sin embargo los órdenes impuestos por ella son universales y eternos ${ }^{11}$.

Es evidente que la historia, si observada superficialmente, parece hecha por los hombres; pero, conocida en su fondo, se revela como generada por la divina providencia. Vico, atento lector de San Agustín, no podía pensar la historia de otra forma que no fuera sostenida por la mano de Dios. De aquí la primera caracterización de la Ciencia nueva como «teología civil razonada de la divina providencia» ${ }^{12}$. Caracterización que está magníficamente mostrada en la pintura alegórica con cuyo comentario se abre el libro: el rayo de luz parte de Dios, y toca la joya cóncava en el pecho de la Metafísica, para reflejarse sobre la estatua de Homero, iluminando por tanto la entera historia humana. Como ha sido justamente observado, la pintura no debe ser «leída» tan sólo recorriéndola de arriba abajo, sino haciendo también en el sentido opuesto: de abajo arriba, de la ingens sylva, habitada por los Gigantes (gegeneîs), por los Terrae filii, hasta la Metafísica, cuyos ojos miran al divino triángulo ${ }^{13}$. Pero hay que decir más: los dos movimientos — de arriba abajo y de abajo arriba — son y han de ser leidos como uno y el mismo movimiento. Si se pierde el sentido de esta unidad-mismidad, no se entiende el objetivo más profundo de Vico. El movimiento proveniente de abajo es el movimiento de lo cierto a lo verdadero, de la auctoritas a la ratio, de la equidad civil a la natural, pero visto a la luz de la mirada divina, del ordo rerum: de lo verdadero eterno, o sea de la mathesis universalis de la historia. No se entienden las historias que «transcurren en el tiempo» más que desde la "historia ideal eterna», desde el "debió debe deberá», que escande el orden necesario - necesario porque eterno- del acaecer histórico. Es bien evidente que en este cuadro problemático las «pruebas filológicas» no pueden sino venir en último lugar, siendo las filosóficas las «pruebas» primeras. Si no fuese ordenada dentro la enkyklopaideía de la filosofía, y ordenada ya de siempre, la filología expondría sólo fragmentos "truncos», "dislocados»—pedazos, escombros $-{ }^{14}$. Mas son "fragmentos dislocados y truncos» únicamente las historias observadas por el ojo insipiente del no-filósofo, o sea de quien no conoce la historia: la historia tout court, ya que sólo en el ordo de la historia ideal eterna se conocen, se pueden conocer los «orígenes, progresos, estados, decadencias y fines» de las historias particulares de las naciones. Lo cual significa que: la

11 Ib., p. 901; curs. mía.

12 Ib., p. 900.

13 Cfr. PACI, E., Ingens sylva. Saggio su Vico, Bompiani, Milano 1944 (2 ed. a cura di V. Vitiello), cap. VIII: «Mito e filosofia». [Véase este grabado al principio de éste número, encabezando el editorial]

14 Cfr. SN44, pp. 903-906. 
philologia es pars philosophiae, al igual que lo cierto es parte de lo verdadero, en cuanto que es de la razón de donde deriva la autoridad (ex ratione auctoritas). La filología es una filosofia implícita, an sich ${ }^{15}$.

Todo esto es bien explícito en Vico, quien, recordando a San Agustín, advierte que la mente humana, «inmersa y sepultada en el cuerpo», debe hacer un esfuerzo por replegarse sobre sí y, haciendo abstracción de lo externo, contemplar en sí misma los principios divinos y eternos que son origen, fundamento y potencia de «su» obrar ${ }^{16}$.

Una profunda distancia separa la relación viquiana entre filosofía y filología de la síntesis kantiana de sensibilidad y entendimiento. Para Kant —como se dice claramente en la crítica a Leibniz ${ }^{17}$ — no es verdad que praedicatum inest subjecto, que el predicado inhiera en el sujeto: porque la «forma» se agrega a la «materia» y es distinta de ella. Por el contrario, en Vico la filosofía - lo verdadero- ex-plicita todo aquello que está ya en la filología —en lo cierto—; dice la verdad implícita, en sí, de la filología. La mathematica divina de la historia no es algo que se agregue a los hechos, porque los hechos están ordenados $a b$ eterno en ella, desde ella y por ella, y sólo por eso son «históricos». Aquí Vico, distante de Kant, está próximo a Leibniz —baste recordar el $\S 8$ del Discours de Métaphysique ${ }^{18}$.

La mathematica divina de la historia, se ha dicho. Y se ha dicho para indicar que Dios —el Dios cristiano, el Deus Trinitas - no es para Vico un postulado de fe, sino el Grundsatz, la proposición fundamental de la ciencia nueva. Sobre este punto, el argumento que Vico aduce en el De uno es particularmente riguroso:

No es del cuerpo la idea del orden eterno, sino que ella es idea de la mente. Y no de mente finita, porque esa idea une a todos los hombres, a todas las inteligencias. La idea del orden eterno es pues idea de una mente infinita. La mente infinita es Dios, o sea que la idea del orden eterno demuestra simultáneamente estas tres verdades: que hay un Dios, que él es una mente infinita, y que él es autor de las verdades eternas, contempladas por nosotros ${ }^{19}$.

15 Para una demostración más articulada de esta relación, remito a Vitiello, V., La favola di Cadmo. La storia tra scienza e mito da Blumenberg a Vico, Laterza, Roma-Bari 1998, pp. 75-110.

16 Sobre el «contemplar» cfr. $S D, O F$, p. 5. Sobre la relación cuerpo-mente y la dificultad de entender, en base a los principios mismos de Vico, cómo la mente pueda «quedar inmersa y sepultada en el cuerpo», remito a Vitiello, V., «Tra natura e storia: l'iconologia della mente», «Il Pensiero», 2002/1, pp. 47-56.

17 Cf. Kant, I., Kritik der reinen Vernunft $(=K r V)$, Apéndice a la Analítica: «Anfibología de los conceptos de reflexión», espec. A 267-268 / B 322-324 (en: Werke, Akademie Textausgabe, de Gruyter, Berlin 1968, vols. III-IV).

18 Cf. Leibniz, G., Philosophische Schriften, Hrsg. C. I. Gerhardt, Berlin 1880; IV, 433.

19 Idea ordinis aeterni idea corporis non est: igitur idea mentis est. Mentis finitae non est, quia omnes homines atque adeo omnes intelligentias unit: igitur idea ordinis aeterni est idea mentis infinitae. Mens infinita Deus est: igitur idea ordinis aeterni haec tria nobis una opera demonstrat: et Deum esse, et mentem unam infinitam esse, et auctorem nobis aeternorum verorum esse. (OG, pp. 42-43). 
Sin Dios no habría historia, y consecuentemente no habría comunidad humana. En verdad, sólo en relación a Dios las cosas tienen «realidad». Leemos en Sobre la antiquísima sabiduría de los ítalos que «únicamente Dios es verdaderamente ente, todos los demás seres son del ente», pertenecen a él («Deus unus [est] vere ens, cetera entis [sunt] potius») ${ }^{20}$. Incluso la autoconciencia, el conocimiento de sí, presupone a Dios:

Verdadera es pues la idea del solo Dios, porque, si él es uno, ello se debe a lo verdadero [...] de modo que «la mente humana» no puede conocerse si no se conoce en Dios. En efecto, la mente se manifiesta pensando, pero es Dios quien piensa dentro de mí, de modo que es en Dios donde conozco mi propia mente $^{21}$.

Es conveniente precisar en este punto que, para el «agustiniano» Vico, el certum es pars veri, que lo cierto participa de lo verdadero, no significa en absoluto que la "sabiduría poética» es una metafísica oculta. Contra «la vanagloria de los doctos, los cuales pretenden que lo que ellos saben es tan antiguo como el mundo» ${ }^{22}$, Vico rechaza «todos los significados místicos de altísima filosofía», atribuidos "a las fábulas griegas y a los jeroglíficos egipcios» ${ }^{23}$. Aquella sabiduría fue "histórica» y no «metafísica». Los poetas griegos «nos han narrado fielmente en sus fábulas el diluvio universal y los gigantes que había habido en la naturaleza, y así nos han narrado con verdad los principios de la historia universal profana ${ }^{24}$. Verdad, razón, filosofía están en lo cierto, en la autoridad, en la filología; pero no son lo cierto, la autoridad, la filología. Están en su fondo y son su fondo. No son su superficie. Considerados en sí y para sí, lo cierto y la autoridad son sólo huellas, signos de aquello que ha sucedido verdaderamente, o sea del genitum, de lo generado, o mejor: del generar divino. Huellas, signos: porque el facere propio del factum, de lo hecho, su hacer específico, no es más que el medio e instrumento inconsciente del obrar divino, un medio que nada sabe de Dios, del verdadero Dios que habita y obra en su propio hacer. Así pues, es la verdad la que conoce lo cierto, y no lo cierto lo que se conoce a sí mismo. Esto explica por qué tolera Dios el orden salvaje de las primeras comunidades. Dios quiere verdaderamente el orden, soportando la ferocidad como medio. Con respecto a lo cierto, a la autoridad y a la filología, consideradas en relación a la verdad, podríamos bien repetir aquello que Vico dice de Aquiles, a saber que también ellas portan «sus "propios" hados bajo los talones» ${ }^{25}$.

20 De antiquissima, Cap. I, II: $O F$, p. 67.

21 «[...] de uno autem Deo idea vera <est>, quia is unus ex vero est. [...] ita ut $<$ mens humana $>$ nec se quoque agnoscat, nisi in Deo se cognoscat. Mens enim cogitando se exhibet: Deus in me cogitat; in Deo igitur meam ipsius mentem cognosco». Ib., Caput VI, OF, pp. 110-111.

22 SN44, Dignidad IV, p. 858.

$23 \quad I b .$, p. 922.

$24 \quad I b .$, p. 929.

25 Ib., p. 1096. 
Pero, de este modo, la mathesis, en vez de explicar la historia, niega de raíz la posibilidad de su comprensión, introduciendo de hecho una escisión insuperable entre lo cierto asumido en lo verdadero y lo cierto en sí, entre la razón y la autoridad, la filosofía y la filología. Asumido en el orden mathematico eterno, lo cierto muda de sustancia y cualidad. Se debe por tanto concluir que no es verdadero que el predicado inhiera en el sujeto, que praedicatum inest subjecto. La filología en sí no es filosofía, o mejor: no es filosofía implícita.

\section{La LENGUA HeRoica}

[...] ahora bien, apenas se puede entender, y de hecho no se puede imaginar cómo pensarían los primeros hombres que fundaron la humanidad gentilicia, pues eran de mentes tan singulares y precisas que consideraban cada nuevo gesto de la cara como una cara nueva [...]; a cada nueva pasión consideraban otro corazón distinto, otro pecho, otro ánimo, de donde provienen aquellas frases poéticas usadas no ya por necesidades métricas, sino por la referida naturaleza de las cosas humanas, cuales son "ora», "vultus», «animi», "pectora», "corda», tomadas éstas [se refiere a las cosas humanas] en singular ${ }^{26}$.

«[...] antes, todas las naciones hablaron escribiendo, igual que aquellas que al principio fueron mudas» ${ }^{27}$. El «hablar escribiendo» de los mudos dice lo mismo que el hablar cantando, pero allí donde este último subraya el momento fonético de la lengua -los monosílabos sonoros-, aquél, el hablar escribiendo, pone de relieve el elemento gestual, propiamente corpóreo del lenguaje. Los «jeroglíficos» que constituían la lengua heroica no eran —es superfluo decirlolos grafitti que los primeros Polifemos, sustraídos a la impiedad por las señales de Júpiter tonante, dejaron en la roca de sus cavernas. Son los mismos «monosílabos sonoros» - el "grito» (der Schrei) del cual hablara Nietzsche, que no conocía a Vico, en La visión dionisíaca del mondo ${ }^{28}$-, las voces inarticuladas que no acompañan a los gestos, porque son los gestos. Estos jeroglíficos son a la vez voz y gesto, gesto y voz y, en este sentido, «palabras reales» ${ }^{29}$ : son las palabras de la «lengua divina mental», «o sea, las ceremonias divinas», y las palabras de la lengua heroica, o sea aquellas que «hablan las armas» ${ }^{30}$. Vico, gran lector del Cratilo, sabía bien que todas las cosas (e.d. tà pràgmata: las cosas trabajadas, las cosas del humano obrar, las cosas reales de la experiencia viva) tienen phonè kai schêma, sonido y figura: perfil. Las cosas, no lo ente (e.d. tà onta: la mera abstracción del objeto) ${ }^{31}$. De hecho, Vico afirma que no es preciso considerar

\footnotetext{
$26 \quad I b .$, p. 1099.

$27 \quad I b .$, p. 943.

28 Cfr. Nietzsche, F., Die dionysische Weltanschauung, en Id., Werke, Kritische Studienausgabe (KSA), Bde. 15, dtv/de Gruyter, München/Berlin-New York 1988, I, p. 575.

29 SN44, pp. 848 e 1223.

$30 I b .$, p. 1172.

31 Cfr. Platone, Cratilo, 423d.
} 
«separados los orígenes de las letras de los orígenes de las lenguas» ${ }^{32}$. Pero las «letras» - los grámmata: los dibujos, las figuras- del «hablar escribiendo» no son los signos de la escritura pictográfica, y menos de la alfabética —conquistas más recientes de la civilización humana-, sino los signos del cuerpo que se inscriben en el espacio haciendo y padeciendo; y al hacer y padecer "canta»: «los mudos exteriorizan sus informes sonidos cantando»; «al cantar, los hombres desfogan sus grandes pasiones» ${ }^{33}$.

Sin embargo, esta gran intuición de la «lengua-gesto», corpórea, o de la cosa como tò pragma constituida de phonè kai schêma, es algo que Vico no posee plenamente, no es un conocimiento estable y seguro. Ya la Dignidad LVII — «Los mudos se expresan mediante actos o cuerpos que guardan relaciones naturales con las ideas que se quieren significar ${ }^{34}$ - puede inducir a error, al distinguir-separar el «gesto vocal» de la idea significada, o la palabra de la cosa, mientras que tal separación surgirá mucho más tarde, como aprendemos del propio Vico que, en la nota 33 al De constantia iurisprudentis, observa:

Así como, antes, la lengua heróica había separado a los héroes de los hombres, así, después, la lengua vulgar separó a los filólogos de los filósofos. El motivo de esta segunda observación es que, dado que la lengua vulgar - en cuanto común - no llegaba a descubrir la naturaleza y la propiedad de las cosas, surgió la escisión entre los filósofos que se dieron a investigar sobre la naturaleza de las cosas, y los filólogos que, en cambio, investigaron sobre el origen de las palabras; y así la filosofía y la filología, que habían nacido las dos de la lengua heróica, vinieron a separarse de la lengua vulgar ${ }^{35}$.

Sobre este punto -o sea sobre el hecho de que la lengua vulgar, en cuanto común, no puede «significar» las cosas- volveremos más adelante. Antes es necesario subrayar lo que se acaba de decir, o sea el hecho de que Vico sea incapaz de dominar su gran intuición. Un ejemplo, de entre los muchos que se podrían aducir: al rey Darío el Grande, que había declarado la guerra al rey escita Idantura, éste le responde enviándole una rana, un ratón, un pájaro, una reja de arado y un arco, con el siguiente significado: que él había nacido en aquella tierra, que en ella había construido su propio techo, que bajo su cielo veneraba a los dioses y allí escrutaba los auspicios, que él había arado sus campos; y que, por todo ello, defendería su tierra con las armas ${ }^{36}$. Es evidente que tales «símbolos» no tienen nada que ver con los «jeroglíficos» sonoros, con

32 SN44, p. 943.

33 Ib., p. 875, Dignidades LVIII y LIX.

34 Ibidem.

35 «[... uti lingua heroica prius heroes ab hominibus diviserat, ita postea lingua vulgaris divisit philologos a philosophis. Cuius secundae observationis ea ratio est, quod, cum lingua vulgi, quia communis, rerum naturas et proprietates non significabat, philosophi in naturis rerum, philologi in originibus verborum investigandis divisi sunt; et ita philosophia ac philologia, quae ab heroica lingua geminae ortae erant, lingua vulgari distractae». (OG, pp. 770771; cursivo mio).

$36 \quad S N 44$, pp. 848 y 948. 
las «voces monosílabas» o «palabras reales»: éstas no remiten a otra cosa que a ellas mismas; son la cosa o las cosas las que expresan ${ }^{37}$; aquéllos: la rana y el ratón, el pájaro, la reja de arado, el arco y sus saetas son, por tanto, «signos» que presuponen una más tardía separación entre palabra y cosa, o sea la escisión de los dos componentes de la "palabra real».

Ciertamente, estos jeroglíficos fonéticos son palabras más antiguas que las de la lengua de Homero, como el propio Vico nos dice en Dignidad XXIX:

En cinco lugares de sus dos poemas [...] se refiere a una lengua más antigua que la suya, que ciertamente fue una lengua heroica, y la llama «lengua de los dioses $»^{38}$.

Es verdad, sin embargo, que a lo largo de la Ciencia Nueva Vico parece cambiar de opinión, allí donde observa, para salvar a Homero de la crítica de Dión Crisóstomo: «dudamos de si quizá, en estos lugares de Homero, hayan de entenderse los "dioses" como "héroes" ${ }^{39}$; una duda que parece diluir más tarde, cuando afirma que "los hombres poderosos de las primeras ciudades» tomaron «el nombre de dioses $»^{40}$.

Vico, que es bien consciente de lo incierto de los límites que separan las dos edades primeras, trata de explicarlo con una afortunada comparación, incluso desde el punto de vista literario: así como las aguas de los ríos — dice-, por el ímpetu de su corriente, penetran largo trecho en el mar sin mezclarse con las otras aguas, así también los caracteres de una edad pueden conservarse algún tiempo en la edad sucesiva ${ }^{41}$; esta incertidumbre es «indicio» de la profunda tensión entre la mathesis universalis y la lengua heroica, en la que se debate la Ciencia Nueva.

La lengua heroica —entendiendo por ésta, no la de Idantura, sino la jeroglifica, la lengua de las «palabras reales»- es incompatible con la mathesis universalis. En efecto, ésta introduce en aquélla una escisión que imposibilita el proyecto viquiano de llevar lo cierto a lo verdadero, la auctoritas a la ratio, la filología a la filosofía. En lo cierto, propio de la lengua heroica, phonè kai schêma son uno y lo mismo. La voz dice, expresa la cosa porque es la cosa misma, tò prágma. El gesto y el significado, el decir —el acto corpóreo del decir- y lo dicho son unum et idem. El «orden» impuesto por los primeros Polifemos, a los que Júpiter tonante hiciera piadosos, es aquel que ellos, a fuerza de gritos y rugidos, lograban imponer, al igual que su dios hablaba con rayos y truenos. Únicamente la mathesis universalis distingue entre el «valor» histórico, «cierto»,

37 Entiéndase bien: las palabras reales que son las cosas mismas, son tà prágmata, las cosas con las que se obra, la unidad de gesto y sonido, no las cosas-objeto, como entiende Battistini que, en sus notas filológicas a la $S N 44$, (cfr. $O$, II, p. 1053, nota 3), se apresura a decir que, para Vico, los primeros hombres se comunicaban «sin mediación de la voz o de la escritura, presentando directamente los objetos que querían designar».

38 SN44, p. 867.

$39 \quad I b .$, p. 950.

$40 \quad I b .$, p. 960.

$41 \quad I b .$, pp. 936 y 1063. 
de aquel orden, y su «valor» verdadero, profundo, metafísico. La mathesis universalis atribuye un «valor añadido» a lo cierto, a la auctoritas, convirtiendo esto en el primer momento de lo verdadero y de la razón. Pero, tomado en sí, lo cierto no es momento de la verdad. Lo es sólo en la mathesis, y por ella.

¿Cómo, entonces, es posible hablar de lo cierto en sí, desde el Standpunkt, el punto de vista de la Ciencia Nueva, que es el de la mathesis universalis? No se trata, obviamente, del hecho que Vico habla de lo cierto en sí; se trata de lógon didónai, de dar razón de este "hecho».

Sin embargo, esta empresa resulta imposible. Porque la mathesis universalis no tiene el lenguaje para decir lo cierto «en sí», sino para distinguirlo de lo cierto en cuanto pars veri. Lo cierto en-sí dice palabras reales: el suyo es el lenguaje concreto de las cosas, de las pràgmata, es el lenguaje individual de las ceremonias religiosas y de las armas, la palabra-gesto del sacerdote que eleva la víctima sacrificial rogando a su dios, el grito del guerrero cuando lanza la jabalina. La lengua heroica es individual; el lenguaje de la ciencia — de la mathesis- es común y universal. Es la «lengua epistolar» de la razón refleja.

Esta diferencia atañe a las raíces de toda la civilización occidental, fundada en la «lógica», o sea en la ciencia, la epistème. Ahora bien, la lógica nace de la separación entre el contenido del decir —o sea, de lo dicho, del significado-, y el gesto corpóreo del decir, de la praxis del decir. Nace de la separación —por seguir con el lenguaje del Cratilo- entre schêma y phonè. El contenido o «significado", tomado de por sí, es el punto de referencia y base de toda construcción lógica, o sea de los principios o fundamentos, sobre los cuales se sostiene tal construcción. El principio de no contradicción, así como lo opuesto de la dialéctica antinómica, se refieren los dos al contenido del decir - al «significado», al «esquema»-, prescindiendo, como debe ser, del pathos de la palabra, del gesto en el que la voz se encarna y es «real». La labor de formalización y simbolización de la lógica descansa en esta separación, que, por lo demás, sigue sin estar investigada. Pero, no sólo la lógica en sentido estricto, sino también el ethos, o sea el modo mismo de relacionarse con el mundo que caracteriza la cultura de occidente, descansa sobre tal separación. Sin la separación entre el "significado» de la palabra y la praxis de la palabra, no sólo cae la distinción verdadero/falso, sino que también lo hacen las distinciones entre bien y mal, útil e inútil, etc. (como comprendió Nietzsche muy bien ${ }^{42}$ ). Y sólo en base a tal separación es posible una mathesis de la historia, y, por ende, buscar un «significado» conservado en la auctoritas de los gegeneîs, los gigantes, de los Terrae filii, los «hijos de la Tierra».

Pero la «lógica» es sólo una parte — la parte «esquemática»— de la lengua. El elemento fonético, pasional, corpóreo, práctico-gestual, que se expresa en el canto y en la escritura de la lengua heroica, queda necesariamente fuera de la lengua vulgar o epistolar. Ésta puede hacerlo su «objeto», constituirlo como significado, schêma, pero, sin embargo, lo transforma de tal modo que lo

42 Cfr. Nietzsche, F., Menschliches, Allzumenschliches, KSA, Bd. 2, I, §§ 1-2. 
traduce en otra cosa, lo traiciona. Qua talis, lo cierto no es pars veri, pars rationis, no participa de lo verdadero, de la razón. Y cuando lo verdadero se apodera de ello, haciéndolo momento o parte de sí mismo, eso de lo que se apodera es sólo la sombra de lo cierto, la apariencia de lo cierto an und für sich. Lo verdadero se crea una imagen de lo cierto y fingit creditque, se figura y se cree que ella, la imagen, es lo cierto.

Ahora bien, la escisión que la razón refleja introduce en el cuerpo vivo de la lengua heroica es contraria a la antropología trinitaria — de origen agustiniano- de Vico, o sea contra la tri-unidad de cuerpo, habla y mente. Hagamos hablar al propio autor. Estamos al final del libro IV de la Ciencia nueva:

[...] no siendo el hombre, propiamente, sino mente, cuerpo y habla, y estando el habla como puesta en medio de la mente y el cuerpo - lo cierto, relativo a lo justo comenzó en las edades mudas del cuerpo; después, descubiertas las lenguas que se llaman articuladas, pasó a las ideas ciertas, o fórmulas de palabras; finalmente, habiéndose desplegado toda nuestra razón, fue a dar en lo verdadero de las ideas en torno a lo justo, determinadas con la razón por las circunstancias últimas de los hechos ${ }^{43}$.

La razón refleja que piensa el orden eterno de la historia ideal es la razón de una mente pura, incorpórea, la razón que se expresa en una lengua abstractamente lógica, mathematica. Aquí sigue siendo ilustrativo un pasaje de la Ciencia Nueva:

Finalmente, demostraremos de buen grado cómo, por encima de este orden de cosas humanas civiles, corpóreo y compuesto, se halle el orden de los números, que son cosas abstractas y purísimas. Los gobiernos comenzaron por el uno, con las monarquías familiares; de ahí pasaron a los pocos, con las aristocracias heroicas; llegaron a los muchos, y aun a ser todos, en las repúblicas populares, en donde todos o la mayor parte constituyen la razón pública; finalmente, retornaron al uno en las monarquías civiles. No hay en la naturaleza de los números división más adecuada que hallarse pueda, ni otro orden que el de uno, pocos, muchos y todos, de modo que los pocos, muchos y todos consideren, cada uno en su especie, la razón del uno; puesto que los números consisten en ser indivisibles, —según dice Aristóteles-; así que, una vez que se ha pasado por todos ellos, se debe recomenzar por el uno. Y lo cierto es que toda la humanidad está comprehendida entre las monarquías familiares y las civiles ${ }^{44}$.

Es necesario evitar un equívoco antes incluso de que surja. No es posible pensar en una recomposición de la unidad de mente y cuerpo mendiante el habla, concibiendo el orden eterno como el horizonte puro de la historia empírica y remitiéndose, si acaso, a la síntesis kantiana de entendimiento y sensibilidad. Porque aquí no está puesto en cuestión el «cuerpo» como contenido del discurso, sino la corporeidad del discurso mismo, del discurso mathematico, epistemico, o sea del eterno ordo rerum, una corporeidad por principio inadmisible.

43 SN44, p. 1229.

$44 \quad I b .$, p. 1220. 
La historia ideal eterna se opone por tanto a la antropología viquiana, o al menos postula su superación. ¿Acaso no había dicho Vico que «únicamente Adam, antes del pecado, fue verdaderamente sabio" (unus Ada integer vere sapiens $\left.^{45}\right)$ ? ¿E incluso que el fin de la filosofía es la unión de la mente con Dios (philosophiae finis unio mentis cum Deo ${ }^{46}$ )? Por lo demás, la evolución política, «real», se opone al diseño de la historia ideal, dado que en la edad de la razón enteramente desplegada sigue siendo necesario que «uno sólo (como Augusto entre los romanos) [...], con la fuerza de las armas, reivindique para sí todas las tareas públicas y deje que los súbditos se ocupen de sus cosas privadas, y se cuiden de las cosas públicas en la medida en que se lo permita el monarca, de modo que, así, se salven los pueblos, los cuales, de lo contrario, se encaminarían a su destrucción $»^{47}$.

Esta tensión no resuelta entre mathesis universalis y lengua heroica es quizás la más alta enseñanza de Vico: de hecho atestigua, no la indigencia de su pensamiento, sino al contrario: su potencia y profundidad. Esta tensión es el problema que Vico nos ha dejado en herencia y que, aún hoy, sigue pasando a menudo inadvertido. El problema del lenguaje de la historia, que se mueve antinómicamente entre la exigencia imprescindible de orden y la necesidad de un novum; o sea, entre el orden, ante todo, del tiempo (baste para ello recordar aquí a Kant: el tiempo permanece y no se muda ${ }^{48}$; el tiempo no transcurre, sino que es en él donde transcurre la existencia de lo mudable ${ }^{49}$ ), sin el cual no es pensable ni siquiera la narración del acaecer histórico, del Geschehen, por un lado, y la novedad por otro lado, sin la cual no tiene ningún sentido hablar de «historia».

Para enfrentarse a este problema, es preciso volver a interrogarse por las categorías modales. Es necesario preguntarse qué es lo que la historia «narra y piensa»: ¿«hechos», o «eventos»? ¿Hechos «reales», o eventos «posibles»?

En las Migajas filosóficas Kierkegaard se pregunta: «¿Es el pasado más necesario que el futuro?» «¿Se ha hecho lo posible más necesario de lo que era por haberse vuelto real? ${ }^{50}$.

La pregunta —Vico docet— no concierne sólo a los «filósofos».

Università San Raffaelle, de Milán

witiello@libero.it

VinCENZO ViTIELLO

[Artículo aprobado para publicación en noviembre de 2013]

45 VIco, G., De constantia jurisprudentis, OG, p. 359.

$46 \quad I b .$, p. 373.

47 SN44, p. 1211.

48 "Die Zeit bleibt und wechselt nicht»: KrV, B 225.

49 "Die Zeit verläuft sich nicht, sondern in ihr verläuft sich das Dasein des Wandelbaren, A 144, B 183.

50 KierkegaArd, S., Migajas filosóficas o un poco de filosofía, ed. y trad. de R. Larrañeta, Trotta, Madrid 1997, (Interludio) p. 81. 